\title{
(6) \\ Health system strategies supporting transition to adult care
} OPEN ACCESS

\author{
Charlotte Moore Hepburn, ${ }^{1,2}$ Eyal Cohen, ${ }^{1,2,3}$ Jasmin Bhawra, ${ }^{1}$ Natalie Weiser, ${ }^{1}$ \\ Robin Z Hayeems, ${ }^{2,3}$ Astrid Guttmann 1,2,3,4
}

\begin{abstract}
${ }^{1}$ Division of Paediatric Medicine, The Hospital for Sick Children, Toronto, Ontario, Canada

${ }^{2}$ Department of Paediatrics, Child Health Policy Initiative, University of Toronto, Toronto, Ontario, Canada

Institute of Health Policy, Management, and Evaluation, University of Toronto, Toronto, Ontario, Canada

${ }^{4}$ Institute for Clinical Evaluative Sciences, Toronto, Ontario, Canada
\end{abstract}

\section{Correspondence to}

Dr Charlotte Moore Hepburn, Division of Paediatric Medicine, The Hospital for Sick Children, 555 University Avenue, Toronto, Ontario, Canada M5G 1X8; charlotte moorehepburn@sickkids.ca

Received 7 August 2014 Revised 27 December 2014 Accepted 27 January 2015 Published Online First 16 February 2015

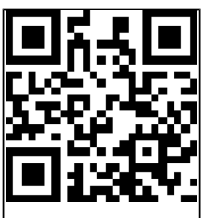

\section{ABSTRACT}

Background The transition from paediatric to adult care is associated with poor clinical outcomes, increased costs and low patient and family satisfaction. However, little is known about health system strategies to streamline and safeguard care for youth transitioning to adult services. Moreover, the needs of children and youth are often excluded from broader health system reform discussions, leaving this population especially vulnerable to system 'disintegration'.

Objectives (1) To explore the international policy profile of paediatric-to-adult care transitions, and (2) to document policy objectives, initiatives and outcomes for jurisdictions publicly committed to addressing transition issues.

Methods An international policy scoping review of all publicly available government documents detailing transition-related strategies was completed using a webbased search. Our analysis included a comparable cohort of nine wealthy Organisation for Economic Co-operation and Development (OECD) jurisdictions with Beveridgestyle healthcare systems (deemed those most likely to benefit from system-level transition strategies).

Results Few jurisdictions address transition of care issues in either health or broader social policy documents. While many jurisdictions refer to standardised practice guidelines, a few report the intention to use powerful policy levers (including physician remuneration and non-physician investments) to facilitate the uptake of best practice. Most jurisdictions do not address the policy infrastructure required to support successful transitions, and rigorous evaluations of transition strategies are rare.

Conclusions Despite the well-documented risks and costs associated with a poor transition from paediatric to adult care, little policy attention has been paid to this issue. We recommend that healthcare providers engage health system planners in the design and evaluation of system-level, policy-sensitive transition strategies.

\section{INTRODUCTION}

In recent years, the number of youth with chronic medical conditions surviving into adulthood has increased. ${ }^{1-4}$ The transition from paediatric to adult care is known to be a period of risk for poor clinical outcomes, as well as increased healthcare costs associated with emergency department visits, hospitalisations and intensive care admissions. ${ }^{1-6}$ Moreover, patients and families have indicated low satisfaction and increased psychological distress during transition. ${ }^{17}$ Given the sensitivity of this critical period, it is imperative that youth with

\section{What is already known about the topic?}

In recent years, there has been a dramatic growth in the number of youth with chronic medical conditions surviving into adulthood.

- Transition from paediatric to adult care is a risk period for poor clinical outcomes, increased healthcare costs and low patient and family satisfaction.

- Successful transition outcomes require coordination across multiple care providers, which necessitates well-articulated health system strategies.

\section{What this study adds?}

- The findings point to the need for evaluating system-level transition strategies and increasing the policy profile.

- This study also serves as a reference point for countries with similar health care systems to design efficient transition-related policies and address policy implementation barriers.

chronic medical conditions are provided seamless transition care. ${ }^{8}$

According to Blum et al, ${ }^{9}$ transition is the "purposeful, planned movement of adolescents and young adults with chronic medical conditions from childcentered to adult- oriented health care systems." A successful transition plan recognises transition as a multifaceted process that engages multiple care providers and accommodates a patient's condition, chronological age and developmental stage. ${ }^{2} 41011$

Many healthcare organisations, including hospitals, have developed transition programmes to help youth exit the paediatric system. However, these programmes are often disease and institution specific, not scalable or universally accessible and remain burdened with capacity and funding barriers. ${ }^{14}$ The complexity of paediatric-to-adult transitions demands system-level solutions that address the alignment of providers in multiple settings, collaboration across various sectors, facilitated communication (including record sharing) and capacity building, all of which commonly demand new, flexible funding arrangements.

Prior studies have not systematically examined system-level strategies designed to streamline and safeguard care for transitioning youth. To address 
this gap, this study explores the international policy profile of the paediatric-to-adulthood transition issue and examines policy objectives, initiatives and outcomes for governments publicly committed to addressing transition care.

\section{METHODS}

An international cross-jurisdictional policy scoping review was conducted. All publicly available government documents detailing paediatric-to-adult care transition strategies were obtained and reviewed. Using an adapted scoping review methodology, ${ }^{12-17}$ we mapped the main sources of evidence and detailed the key concepts related to health system strategies supporting paediatric-toadult care transitions. ${ }^{14} 17$

Scoping studies allow researchers to explore the depth and breadth of current activity, identify knowledge gaps and summarise and disseminate findings. ${ }^{14}$ These studies are commonly policy-oriented to facilitate an understanding of the current policy context, guide further research and prioritise future applied endeavours. ${ }^{15} 16$

The international scan included nine wealthy Organisation for Economic Co-operation and Development (OECD) jurisdictions with Beveridge-style healthcare systems. A Beveridge-style system is a universal, publicly funded healthcare system financed through general taxation. ${ }^{18}$ Australia, Canada, Denmark, Finland, Ireland, New Zealand, Norway, Sweden and the UK were selected to represent comparable health systems, most likely to benefit from system-level transition strategies and most capable of applying lessons learnt from similar jurisdictions. While all of the countries selected satisfy the Beveridge-style criteria, there are notable differences between these countries with respect to the proportion of public expenditure on health. For example, in 2012, New Zealand spent US\$3172 per person, compared with Norway, which spent US\$6140 per person. ${ }^{19}$

For countries where healthcare funding and policy vary by states or provinces (Canada and Australia), we included an assessment at this level of jurisdiction. In the case of Australia, policy differs between states and territories, hence the search was conducted by region. For the UK, we looked to policy documents that would cover all of the UK, although decisions would be implemented by local health services in Scotland, Wales, Northern Ireland and England.

The scoping review took place between 6 March 2014 and 15 May 2014, and entailed a 3-step search strategy. First, official government websites (specifically, health-focused and childfocused departments and/or ministries) were searched for transition-related documents. The search was conducted using a standard search engine (ie, Google) and a direct search of government websites. The search strategy included the combined use of multiple search terms, including "paediatric," "adolescent," and/or "youth," and "transition," "transition to adult health care," "strategy" and/or "policy." Unique searches were conducted for all nine countries (ie, "Norway" and "paediatric" and "transition" and "policy"). In this study, 'strategy' refers to a government action plan explicitly designed to address key issues related to the paediatric-to-adult care transition. Strategies may include high-level, system-organising frameworks, pilot initiatives and/or funding opportunities (planned or in progress). 'Policy' refers to fixed elements of strategy, formally adopted and universally applied by government(s).

Second, national professional medical and academic associations were contacted to corroborate whether all relevant government documents had been obtained. Third, government representatives (identified on government websites as appropriate contacts) were contacted to confirm that all publicly available documents were identified through scoping review steps one and two.

Content from non-English websites was translated into English using the web-based translation service Google Translate. Google Translate allows for 'operationally workable' English versions of non-English text. ${ }^{20}$ The accuracy of translation is dependent on the original language. In our study, Google Translate was only used to translate webpage content. We did not require Google Translate to translate government documents, as no documents were uncovered in non-English speaking countries.

Information from all publicly available transition documents was abstracted and organised by country into the following nine categories agreed upon as most relevant by the research team (including a former policymaker): (1) Strategic Vision/ Mission/Principles, (2) Definitions, (3) Age of Transition, ${ }^{9}$ (4) Targeted Diseases, (5) Targeted Investments (ie, funding for pilot programmes), (6) Financial Incentives (ie, specific payments provided for transition-related appointments), (7) Non-Financial Incentives (ie, professional/caregiver/patient education programmes), (8) Information Systems (ie, data sharing platforms) and (9) Evaluation. The nine data abstraction categories reflect fundamental elements of policy development, and would serve as the building blocks for policy addressing this issue. Documents were included if they were publicly available and detailed government strategies or policies related to paediatric-to-adult healthcare transition. Documents were excluded if content discussed transition as a broad social phenomenon (ie, transitioning from school to employment) without specific mention of transition from paediatric to adult healthcare. Best practice documents linked to government websites, produced and published by professional societies (independent from government), were also excluded.

The scoping review used a team approach to ensure that the data collection process was transparent and replicable. ${ }^{14}$ Two research coordinators independently extracted data from government documents using the data abstraction table, and met routinely to ensure the approach to data extraction was consistent with the research questions and goals. There were no points of disagreement requiring formal reconciliation throughout the review process.

\section{RESULTS}

A total of 92 websites were visited, and 33 government officials and 15 professional associations were contacted during the scoping review. Fifty-two transition-related documents were identified. Ten of these documents explicitly discussed the transition from paediatric to adult care. The remaining documents $(n=42)$ were excluded because they discussed transition exclusively outside of the scope of healthcare or referred to independently published best practices. Figure 1 provides an overview of the search results.

While several jurisdictions indicated an interest in addressing transition issues and published documents commenting on the need to develop a transition strategy as a 'next step' for future work, only two published documents detailing a paediatricto-adult care transition strategy. Table 1 provides an overview of the findings from countries without an operational government strategy. Table 2 outlines the transition strategies detailed by Australia and the UK.

Australia and the UK, in particular England, were the only two countries that published documents detailing governmentsupported transition strategies. In 2008, the British government developed the Transition Support Programme which aimed to 


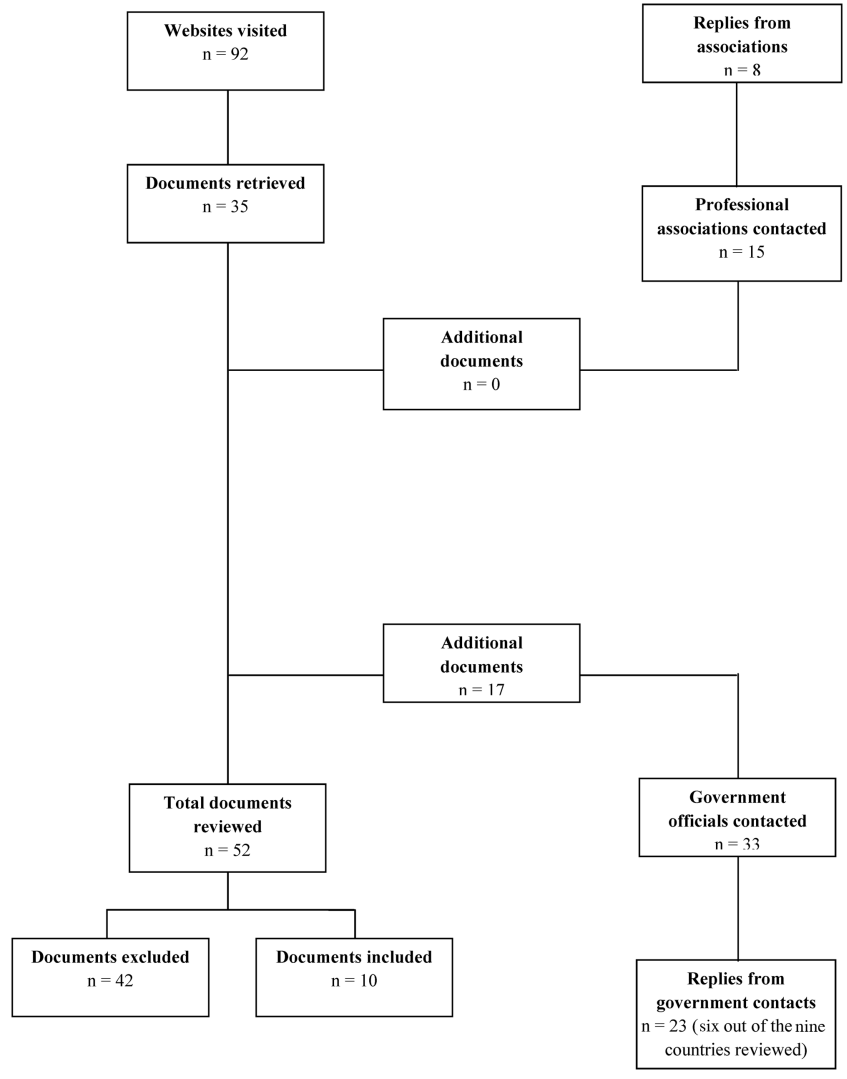

Figure 1 Search results.

provide support for every aspect of a disabled and young people's transition to adulthood (ie, education, employment and healthcare). ${ }^{22}{ }^{26}$ Between 2008 and 2011, through the Transition Support Programme, England provided 11 regions (comprised of 152 local areas) with funding to develop transition initiatives. However after 2011, many of the local transition initiatives were not sustained due to funding issues. ${ }^{25}$
In 2005 , new transition clinics for patients with complex disabilities (eg, cerebral palsy) were piloted in adult health centres in Victoria, Australia. Features of successful pilot clinics are informing a generic service model for widespread implementation across Victoria. In parallel, the Victorian Paediatric Clinical Network, a clinical network supported by the Victoria Department of Health, is preparing a broad set of principles for transition based on guidance from the Royal Australasian College of Physicians. Table 2 summarises the paediatric-to-adult transition care strategies employed by Australia and England.

\section{DISCUSSION \\ Opportunities for knowledge translation and knowledge creation}

This international cross-jurisdictional policy scoping reveals that transition has received little government attention. Consequently, it underscores the need to translate existing evidence on the cost, quality and patient satisfaction-related implications of transition to governments for the purpose of elevating the profile of this important issue.

\section{Knowledge and knowledge gaps from leading jurisdictions}

Australia and the UK have demonstrated efforts to develop paediatric-to-adult transition strategies offering important lessons to other jurisdictions. First, both have applied existing evidence, where possible, in the design of their health system strategy. Both employed expert-derived definitions of highquality transition care (Blum et al, ${ }^{9}$ emphasising transition as a process instead of a one-time transfer. ${ }^{26-31}$ Both jurisdictions recognised that transition is not a generic 'one size fits all' process, must vary depending on a patient's clinical, social or emotional 'readiness' and must accommodate both diseasespecific and individual-driven needs (eg, transition plans should vary by condition, be culturally sensitive and attuned to rural vs urban concerns). This necessary flexibility is highlighted by both Australia and the UK in their position that transition may start as early as 13 , contrary to the commonly held position that paediatric care stops at a fixed age.

Table 1 Cross-jurisdictional scan summary

\begin{tabular}{|c|c|c|}
\hline Country & $\begin{array}{l}\text { Number of publicly available } \\
\text { documents discussing } \\
\text { paediatric-to-adult } \\
\text { transition needs }\end{array}$ & Document overview \\
\hline Ireland & 6 & $\begin{array}{l}\text { Published documents outlining the needs associated with chronic disease care (specifically for disabled } \\
\text { children). }{ }^{21} 22 \\
\text { Recently released a strategy document called "Better Outcomes Better Futures: The National Policy } \\
\text { Framework for Children and Young People, 2014-2020" where the issue of transition is mentioned; } \\
\text { however, concrete government strategies are not discussed. }{ }^{23}\end{array}$ \\
\hline New Zealand & 3 & $\begin{array}{l}\text { Published documents outlining the needs of children and young people with chronic conditions and } \\
\text { disabilities. } \\
\text { Transition was mentioned; however, a government strategy was not discussed. }\end{array}$ \\
\hline Canada & 8 & $\begin{array}{l}\text { Referred to work performed by non-governmental agencies. } \\
\text { Transition was mentioned and the ON TRAC documents provide guidelines for chronic conditions at a system } \\
\text { level; however, a government strategy was not discussed. }{ }^{24}\end{array}$ \\
\hline Finland & 0 & - There are currently no transition policies or strategies in action in Finland. \\
\hline Denmark & 0 & - There are currently no transition policies or strategies in action in Denmark. \\
\hline Norway & 0 & $\begin{array}{l}\text { Norwegian Paediatric Associations communicated that there are currently no transition policies or strategies } \\
\text { in action in Norway. } \\
\text { - The government of Norway did not reply to email requests to confirm the absence of transition documents. }\end{array}$ \\
\hline Sweden & 0 & $\begin{array}{l}\text { Swedish Paediatric Associations communicated that there are currently no transition policies or strategies in } \\
\text { action in Sweden. } \\
\text { The government of Sweden did not reply to email requests to confirm the absence of transition documents. }\end{array}$ \\
\hline
\end{tabular}


Table 2 Overview of findings from cross-jurisdictional scan for Australia and the UK

\begin{tabular}{|c|c|c|}
\hline & Australia & The UK \\
\hline Policy & \multicolumn{2}{|c|}{$\begin{array}{l}\text { Both countries released high-level strategies and/or pilot programme investments; however, neither government has implemented system-wide } \\
\text { policies related to transition of care. }{ }^{25} \text {-30 }\end{array}$} \\
\hline $\begin{array}{l}\text { Vision, Mission and } \\
\text { Principles }\end{array}$ & \multicolumn{2}{|c|}{$\begin{array}{l}\text { Both countries highlight the need for young people to take responsibility for their health and well-being, the importance of patients' ownership } \\
\text { over transition and the value of well-coordinated care. } \\
\text { Both countries highlight the need for: } \\
\text { - Specialised supports to optimise accessibility for rural and vulnerable groups. } \\
\text { - Appropriate services (ie, culturally sensitive, relevant to a variety of disease and/or chronic conditions). }\end{array}$} \\
\hline $\begin{array}{l}\text { Definition of } \\
\text { Transition }\end{array}$ & \multicolumn{2}{|c|}{$\begin{array}{l}\text { The definition of transition varies slightly; however, both countries' definitions derive from Blum et al: }{ }^{9} \text { " }[\text { Transition is] the purposeful, planned } \\
\text { movement of adolescents and young adults with chronic physical and medical conditions from child-centered to adult oriented health care } \\
\text { systems." } 31\end{array}$} \\
\hline Age of Transition & \multicolumn{2}{|c|}{$\begin{array}{l}\text { Both countries suggest planning for transition as early as possible (at } 13 \text { or } 14 \text { years of age); however, the precise age of active transition is } \\
\text { expected to vary according to the patient and the condition. } \\
\text { No specific age to initiate the transition process is suggested by either government. } 26283031\end{array}$} \\
\hline Targeted Diseases & $\begin{array}{l}\text { Australia identifies young people with neurological disorders and } \\
\text { chronic disability as requiring special consideration for planning and } \\
\text { delivery of transition services. } \\
\text { Australia also notes that some young people may need to transition } \\
\text { from paediatric to adult palliative care (ie, those with metabolic } \\
\text { disorders or respiratory failure). }{ }^{28}\end{array}$ & $\begin{array}{l}\text { The UK identifies children with disabilities, chronic conditions and } \\
\text { mental health concerns as priority populations with respect to } \\
\text { transition. }{ }^{21} 27\end{array}$ \\
\hline $\begin{array}{l}\text { Targeted } \\
\text { Investments }\end{array}$ & $\begin{array}{l}\text { Transition care coordinators have been appointed in Australia, and the } \\
\text { Agency for Clinical Innovation is working with the New South Wales } \\
\text { Transition Care Network to find other ways of improving healthcare } \\
\text { delivery and youth's experience with transition. }\end{array}$ & $\begin{array}{l}\text { The UK invested } f 19 \text { million in the Transition Support Programme to } \\
\text { facilitate better transition programming for children and youth with } \\
\text { complex conditions and disabilities. This represented one-time } \\
\text { funding, with no sustainable ongoing monies pledged. }{ }^{25} 27\end{array}$ \\
\hline Financial Incentives & $\begin{array}{l}\text { Australia identified the difficulties associated with episode-based } \\
\text { funding models for funding non-episode-based activity (ie, transition); } \\
\text { however, no alternative funding models have been proposed. }\end{array}$ & $\begin{array}{l}\text { Through the Transition Support Programme, England provided } 11 \\
\text { regions funding to develop transition initiatives from } 2008 \text { to } 2011 \text {. } \\
\text { After } 2011 \text {, many of the local transition initiatives were not sustained } \\
\text { due to lack of ongoing monies. }{ }^{25} 27\end{array}$ \\
\hline $\begin{array}{l}\text { Non-Financial } \\
\text { Incentives }\end{array}$ & \multicolumn{2}{|l|}{ No non-financial incentives for transition were detailed in either jurisdiction. } \\
\hline $\begin{array}{l}\text { Information } \\
\text { Strategies }\end{array}$ & \multicolumn{2}{|l|}{ - No system-wide information sharing strategies were detailed in either jurisdiction. } \\
\hline Evaluation & - No evaluation plans are publicly available. & $\begin{array}{l}\text { Evaluations have been conducted for the Transition Support } \\
\text { Programme. } \\
\text { Results indicate varying levels of participation and programme quality } \\
\text { across England, as many local areas did not have a funding structure } \\
\text { after } 2011 \text {. } \\
\text { The domains of evaluation related to health were limited. }{ }^{25}\end{array}$ \\
\hline
\end{tabular}

These leading jurisdictions should be commended for acknowledging and attempting to provide flexibility associated with successful transition planning, as flexibility is challenging to implement at a system level. Policies are traditionally fixed standards, universally applied to a population based on established, clearly understood criteria. Flexible 'policies' demand that governments generate, apply and monitor novel practices, potentially causing both unmanageable expectations and complex public service workloads. Both of these possible consequences would have to be carefully evaluated following large-scale strategy implementation.

Second, the UK recognised the importance of dedicated funding by piloting a transition programme in England. Unlike other jurisdictions that acknowledged the need for increased funding without committing additional financial resources, England provided local areas with temporary funding to facilitate the development of transition systems. Other new developments include a government-appointed National Clinical Director for Children, Young People, and Transition to Adulthood as part of National Health Services (NHS) England. ${ }^{33}$ Additionally, NHS has been working on developing a generic approach to transition care in England, ${ }^{34}$ and the National Institute for Health and Care Excellence (NICE) is in the process of developing a guidance document on transition to be published in February 2016. ${ }^{35}$
While it was encouraging to see the UK investing directly in transition care, it was clear from strategy evaluations that maintaining funding is an issue. Moreover, this pilot programme was only implemented in England and not throughout the UK. This highlights the need for sustained funding for high-quality transition systems following positively evaluated pilot programmes.

Australia acknowledged that episode-based funding limits a health system's ability to implement transition plans, as transition care requires communication and care coordination above and beyond the traditionally billable 'care episode'. However, the strategy provided no alternatives to episode-based funding. This highlights the need for further research into which funding models or incentives best align with various system-level transition policies. While some may advocate for financing clinics, other might advocate for creating non-clinic-based financing structures to accommodate additional costs associated with cross-sectoral provider case conferencing or information sharing. Importantly, little comparative effectiveness work has been completed in this area, leaving unknown which financing strategies are the most effective and/or suitable for application in Beveridge-style healthcare systems. Further research should explore those policy levers to best support youth through transition.

Third, both Australia and the UK highlighted the need for cross-sectoral collaboration acknowledging that transition is not 
exclusively a health system issue, especially for youth with complex conditions. Successful transition requires attention from government across many sectors, including, but not limited to health, education and social services. In addition, there are a multitude of stakeholders, including patients, families and advocacy groups, each of whom have unique perspectives on, roles in and interests regarding transition. ${ }^{5}$ The diversity of governmental and non-governmental stakeholder groups requires well-organised channels of communication and effective methods of coordination, further highlighting the need for system-level strategies. ${ }^{3136}$

However, there are both political and logistical challenges associated with cross-sectoral cooperation and integration, as leadership, accountability, regulations and budget structures vary across sectors. The successful adoption of comprehensive transition policy will require clarity around which group(s) are responsible (from both a legislative perspective and a financial perspective) for each component of the process. ${ }^{11}{ }^{36}$ Expertise in cross-sectoral governance and collaboration should accompany knowledge translation efforts to ensure a comprehensive approach to the paediatric-to-adult care challenge. One of the recognised shortcomings of the UK strategy related to inconsistent and incomplete information sharing, limiting the ability of cross-sectoral care providers to share patient/client data and best evidence, and to build learning-oriented communities of practice. As capacity and political appetite for cross-sectoral governance builds, a logical first step may be the creation of novel, cross-sectoral information sharing platforms.

Lastly, moving forward, it will be essential to ensure that systemlevel strategies in new jurisdictions are accompanied by robust evaluation. While the UK published a programme-oriented evaluation that was limited in scope, Australia has not published an evaluation of its initiative. The need to constructively communicate lessons learnt both within and across jurisdictions will be key to advancing the transition agenda internationally.

\section{Limitations of the study}

While this scoping review provides valuable cross-jurisdictional insights, several limitations exist. First, not all government strategies are outlined in publicly available documents. It is possible that other strategic works are underway. This potential limitation was addressed by contacting professional medical associations and government bodies directly to corroborate the search results. Additionally, because our search was limited to only government documents, we acknowledge that not all transition strategies within a country may have been captured. However, we limited the scope of the search to focus on government policies and strategies rather than clinical guidance or advocacy by organisations such as professional associations. Our main interests were the potential policy levers and frameworks designed at the system level.

Finally, given that our search parameters were limited to wealthy OECD countries with Beveridge-style systems, innovations in other health systems were missed.

\section{CONCLUSION}

Although transitions of care have received much attention in the child health community, little government attention has been paid to this complex health system issue. While policy frameworks are not sufficient for change, they are an important first step in improving transition from paediatric to adult care.

Acknowledgements We thank Dr Walter Wodchis for leadership on the Health System Performance Research Network grant and constructive ideas related to this work, as well as Drs Julia Orkin and Alene Toulany for their helpful feedback on the manuscript draft. We also wish to thank the government officials and professional organisation representatives in the nine jurisdictions reviewed who responded to our queries.

Contributors $\mathrm{CMH}$ conceived the idea for the paper, supervised the activities of the research team and reviewed, edited and approved the manuscript. JB and NW conducted data collection and abstraction for the study, drafted the initial and revised manuscripts and reviewed and approved the manuscript. EC contributed ideas to the study design, assisted in the interpretation of the data and reviewed and approved the manuscript. RH assisted in the interpretation of the data and reviewed and approved the manuscript. AG obtained funding for the study, provided strategic oversight for the research team, contributed ideas to the study design, assisted in the interpretation of the data and edited and approved the manuscript.

Funding Funding was provided by the Ontario Ministry of Health (Health System Research Fund for the Health System Performance Research Network). AG is supported by the Canadian Institute for Health Research Applied Chair in Health Services Research.

\section{Competing interests None.}

Provenance and peer review Not commissioned; externally peer reviewed.

Data sharing statement The results of the cross-jurisdictional scan were shared through a poster presentation at the Paediatric Academic Societies 2014 conference.

Open Access This is an Open Access article distributed in accordance with the Creative Commons Attribution Non Commercial (CC BY-NC 4.0) license, which permits others to distribute, remix, adapt, build upon this work non-commercially, and license their derivative works on different terms, provided the original work is properly cited and the use is non-commercial. See: http://creativecommons.org/ licenses/by-nc/4.0/

\section{REFERENCES}

1 Baines J. Promoting better care: transition from child to adult services. Nurs Stand 2009;23:35-40

2 Campbell F, O'Neill PM, While A, et al. Interventions to improve transition of care for adolescents from paediatric services to adult services. Cochrane Database Syst Rev 2012:4:1-11.

3 Crowley R, Wolfe I, Lock K, et al. Improving the transition between paediatric and adult healthcare: a systematic review. Arch Dis Child 2011;96:548-53.

4 Grant C, Pan J. A comparison of five transition programmes for youth with chronic illness in Canada. Child Care Health Dev 2011;37:815-20.

5 British Columbia Medical Association. Closing the gap: Youth transitioning to adult care in BC. https://www.doctorsofbc.ca/files/1984BCMA\%20Youth\%20Transitions. web_.pdf (accessed 26 Feb 2014).

6 Cooke E. Transitional care for young people with diabetes: policy and practice. Pediatr Nurs 2007;19:19-22.

7 Sonneveld HM, Strating MM, van Staa AL, et al. Gaps in transitional care: what are the perceptions of adolescents, parents and providers? Child Care Health Dev 2012;39:69-80.

8 American Academy of Pediatrics (AAP). Clinical Report-Supporting the health care transition from adolescence to adulthood in the medical home. Pediatrics 2011;128:182-200

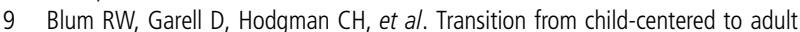
health-care systems for adolescents with chronic conditions: a position paper for the Society for Adolescent Medicine. J Adolsc Health 1993;14:570-6.

10 The Royal Australasian College of Physicians. Transition to adult health services for adolescents with chronic conditions. http://www.racp.ed.au (accessed 7 Feb 2014).

11 Viner R. Transition of care from paediatric to adult services: one part of improved health services for adolescents. Arch Dis Child 2008;93:160-3.

12 Daudt $\mathrm{H}$, van Mossel C, Scott S. Enhancing the scoping study methodology: a large, inter-professional team's experience with Arskey and O'Malley's framework. BMC Med Res Methodol 2013;13:48.

13 Valaitis R, Martin-Misener R, Wong S, et al. Methods, strategies and technologies used to conduct a scoping literature review of collaboration between primary care and public health. Prim Health Care Res Dev 2012;13:219-36.

14 Levac D, Colquhoun H, O'Brien K. Scoping studies: advancing the methodology. Implement Sci 2010;5:69.

15 Davis K, Drey N, Gould D. What are scoping studies? A review of the nursing literature. Int J Nurs Stud 2009;46:1386-400.

16 Anderson S, Allen P, Peckham S, et al. Asking the right question: scoping studies in the commissioning of research on the organization and delivery of health services. Health Res Policy Syst 2008;6:7

17 Arskey H, O'Malley L. Scoping studies: towards a methodological framework. Int Soc Res Methodol 2005;8:19-32.

18 Arah OA, Klazinga NS, Delnoij DM, et al. Conceptual frameworks for health systems performance: a quest for effectiveness, quality and improvement. Int I Qual Health Care 2003;15:377-98 
19 The Commonwealth Fund. Country Comparison. 2014. http://www. commonwealthfund.org/interactives-and-data/us-compare-interactive\#?ind=1 (accessed 1 Nov 2014).

20 Balk $E$, Chung $M$, Chen $M$, et al. Data extraction from machine-translated versus original language randomized trial reports: a comparative study. Syst Rev 2013;2:97.

21 Department of Health, Department for Education and Skills. National Service Framework for Children, Young People, and Maternity Services: Disabled Children and Young People and those with Complex Health Needs. March 2006. http:// webarchive.nationalarchives.gov.uk/20130107105354/http://www.dh.gov.uk/prod_ consum_dh/groups/dh_digitalassets/@dh/@en/documents/digitalasset/dh_4132149. pdf (accessed 26 Mar 2014).

22 Department of Children and Youth Affairs. National strategy for research and data on children's lives 2011-2016. November 2011. http://www.dcya.gov.ie/viewdoc. asp?fn=/documents/Publications/NSRD_summary.pdf (accessed 25 Feb 2014).

23 Ministry for Children and Youth Affairs. Better outcomes brighter futures: The national policy framework for children and young people 2014-2020. April 2014. http://dcya.gov.ie/documents/cypp_framework/BetterOutcomesBetterFutureReport.pdf (accessed 25 Feb 2014).

24 Paone $\mathrm{M}$, Whitehouse S. ON TRAC transitioning responsibility to adult care: A transition initiative for youth and young adults with chronic health conditions and/or special needs in British Columbia. http://ontracbc.ca/wp-content/uploads/ ON-TRACBackground2011.pdf (accessed 18 Feb 2014).

25 National Transition Support Team. The Transition Support Programme: Improving support for disabled young people in transition to adulthood. http://webarchive. nationalarchives.gov.uk/20110809101133/http://www.transitionsupportprogramme. org.uk/PDF/NTST_TSP_Year3_Information_SheetV2.pdf (accessed 2 Apr 2014).

26 Department for Children, Schools, and Families, Department of Health. Transition: Moving on well. A good practice guide for health professionals and their partners on transition planning for young people with complex health needs or a disability. February 2008. http://www.bacdis.org.uk/policy/documents/transition moving-on-well.pdf (accessed 27 Feb 2014).
27 HM Treasury, Department for Education and Skills. Aiming high for disabled children: better support for families. May 2007. http://webarchive.nationalarchives.gov.uk/ 20130401151715/https://www.education.gov.uk/publications/eOrderingDownload/ PU213.pdf (accessed 26 Mar 2014).

28 Western Australia Child and Youth Network. Paediatric chronic diseases transition framework. November 2009. http://www.healthnetworks.health.wa.gov.au/modelsofcare/ docs/Paediatric_Chronic_Diseases_Transition_Framework.pdf (accessed 5 Feb 2014).

29 Victorian Government Department of Human Services. Strategic framework for paediatric health services in Victoria. April 2009. http://www.health.vic.gov.au/ childrenatrisk/documents/paediatric_framework.pdf (accessed 5 Feb 2014).

30 New South Wales Agency for Clinical Innovation. Transition care for young people with chronic childhood illnesses. April 2006. http://www.aci.health.nsw.gov.au/ data/assets/pdf_file/0010/155719/final_framework.pdf (accessed 18 Mar 2014).

31 Department of Health, Department for Education and Skills. National Service Framework for Children, Young People, and Maternity Services. Transition: Getting it right for young people. Improving the transition of young people with long-term conditions from children's to adult's health services. March 2006. http://webarchive. nationalarchives.gov.uk/20130107105354/http://www.dh.gov.uk/prod_consum_dh/ groups/dh_digitalassets/@dh/@en/documents/digitalasset/dh_4132149.pdf (accessed 26 Mar 2014).

32 NSW Agency for Clinical Innovation. Transition Care Network. 2014. http://www.aci. health.nsw.gov.au/networks/transition-care (accessed 15 Dec 2014).

33 NHS England. National Clinical Directors. 2014. http://www.england.nhs.uk/about/ whos-who/ncd/\#chi (accessed 6 Nov 2014).

34 NHS UK. Improving quality: Children and young people's transition to adult services 2014. http://www.nhsiq.nhs.uk/7861.aspx (accessed 6 Nov 2014).

35 National Institute for Health and Care Excellence (NICE). Transition from children's to adult services. 2014. http://www.nice.org.uk/Guidance/InDevelopment/GID-SCWAVE0714 (accessed 6 Nov 2014).

36 Viner R. Transition from paediatric to adult care. Bridging the gaps or passing the buck? Arch Dis Child 1999;81:271-5. 